\title{
Pulmonary artery sarcoma masquerading as subchronic pulmonary thromboembolism
}

\author{
Hagen Kahlbau, M.D. ${ }^{1 *}$ | Helena Telles Antunes, M.D. ${ }^{1} \quad$ | Ines Rodrigues, M.D. ${ }^{2}$ | \\ Rita Carvalho, M.D. ${ }^{3}$ | José Fragata, M.D., Ph.D. ${ }^{1 *}$
}

${ }^{1}$ Department of Cardiothoracic Surgery, Hospital de Santa Marta, Lisbon, Portugal

2 Department of Cardiology, Hospital de Santa Marta, Lisbon, Portugal

3 Department of Pathology, Centro Hospitalar Lisboa Central, Lisbon, Portugal

${ }^{*}$ Correspondence

Hagen Kahlbau, M.D., Department of Cardiothoracic Surgery, Hospital de Santa Marta, Rua de Santa Marta 50, 1169-1024 Lisbon, Portugal.

Email: hagenkahlbau@gmx.de

\section{1 | CASE PRESENTATION}

A 50-year-old male presented with increasing shortness of breath. A chest computed tomography (CT) scan showed extensive filling defects involving the main pulmonary artery (PA) and its major and segmental branches (Figure 1). The patient was started on intravenous heparin but there was no change in the size of the mass on a transthoracic echocardiogram. In view of this, the patient was taken to the operating room to make a definitive diagnosis, and was placed on cardiopulmonary bypass via a median sternotomy with central aortic and bicaval cannulation. The mass was seen invading the left, lateral inferior portion of the PA (Figure 2). Following cardioplegic arrest, a longitudinal incision was made in the main PA and a solid mass was noted to extend proximally

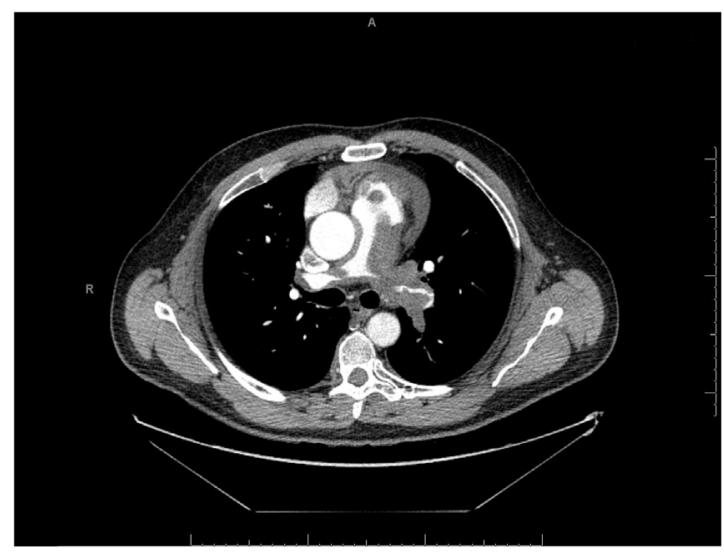

FIGURE 1 CAT scan showing mass infiltration of the pulmonary artery on the level of the bifurcation through the pulmonary valve into the right ventricular outflow tract and distally to beyond the bifurcation of the right and left PA (Figure 3). A tumor debulking procedure was performed, as it was not possible to resect this infiltrating mass. The PA was closed with a running 4-0 prolene suture. The patient tolerated the procedure well and had an uncomplicated postoperative course. The final pathology was consistent with a pleomorphic sarcoma (Figure 4). The patient was referred for adjuvant therapy.

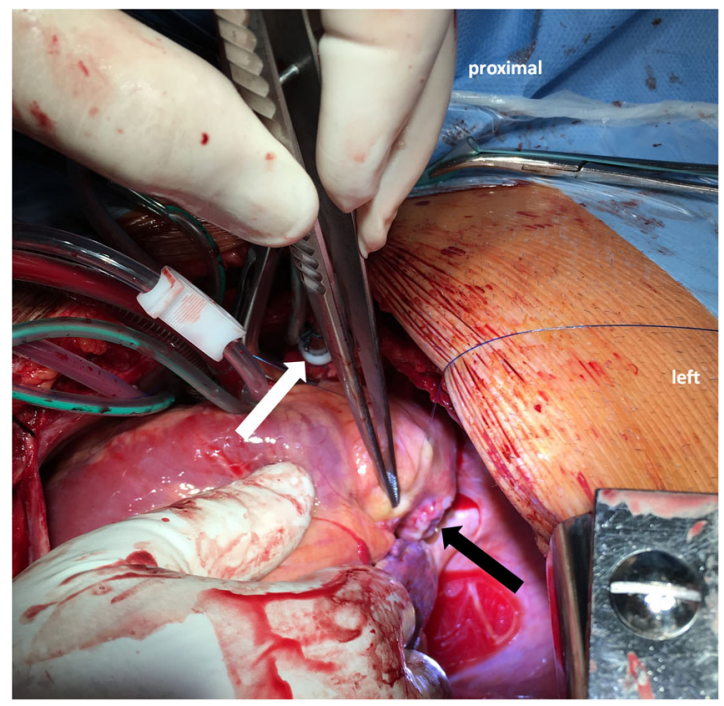

FIGURE 2 Intraoperative image of inferior wall infiltration of the pulmonary artery (black arrow); white arrow = the aortic cannulation 


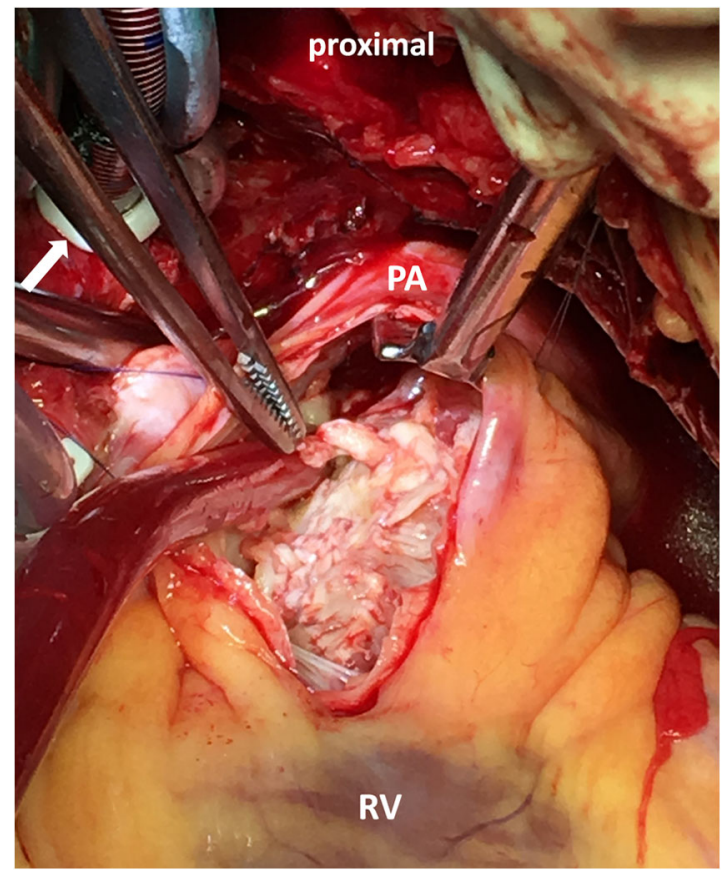

FIGURE 3 Intraoperative image showing the longitudinally opened pulmonary artery with mass formation. PA, pulmonary artery; RV, right ventricle

\section{ACKNOWLEDGEMENTS}

We thank the Department of Clinical Pathology and Eugenia Pinto, MD for the image of the hematoxylin and eosin stain study and the

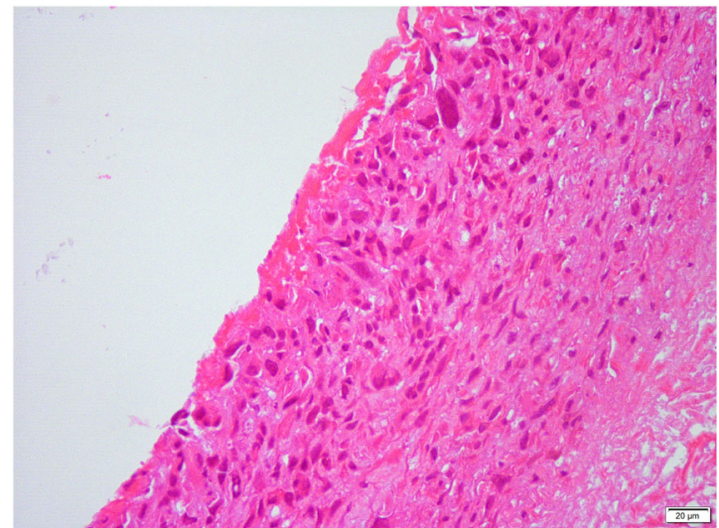

FIGURE 4 Hematoxylin and eosin stain study of the intraoperative biopsy

department of cardiology (Luisa Branco, MD and Ana Galrinho, MD) for echocardiography assessment in this case.

\section{CONFLICT OF INTEREST}

The authors acknowledge no conflict of interest in the submission. 